\title{
ASSOCIATION OF HYPERTENSION AND DIABETIC RETINOPATHY IN TYPE 2 DM PATIENTS.
}

1. MBBS, FCPS

Associate Professor Medicine Independent Medical College, Faisalabad.

2. MBBS, FCPS

Associate Professor Medicine Independent Medical College, Faisalabad.

3. MBBS, FCPS

Associate Professor Medicine Independent Medical College, Faisalabad.

4. MBBS, MRCP

Assistant Professor Medicine Independent Medical College, Faisalabad.

5. MBBS, FCPS

Associate Professor Medicine Aziz Fatima Medical \& Dental College, Faisalabad.

6. MBBS, FCPS (Medicine), FCPS (Hematology) Assistant Professor Medicine Independent Medical College, Faisalabad.

Correspondence Address:

Dr. Ali Saqib

House No. 2, Chandni Street, Alnajaf Colony, Faisalabad. alisaqib74@hotmail.com

Article received on: 08/11/2019 Accepted for publication: $24 / 07 / 2020$

\begin{abstract}
Ali Saqib', Muhammad Sarfraz², Touseef Anwar ${ }^{3}$, Muhammad Absar Alam4, Rizwan Rasul Khan ${ }^{5}$,
\end{abstract} Zafar Ali Zafar ${ }^{6}$

ABSTRACT... Objectives: To evaluate the association of hypertension and diabetic retinopathy in type 2 DM patients. Study Design: Case Control study. Setting: Diabetic Clinic Department of Medicine, Independent University Hospital, Faisalabad. Period: From January 2019 to June 2019. Material \& Methods: One Hundred Type 2 diabetic patients of either sex were reviewed and these patients were screened for diabetic retinopathy using welchallyn ophthalmoscope. The patients with diabetic retinopathy fulfilling the inclusion criteria were placed in group A (cases) and patients without diabetic retinopathy were placed in group B (control). After resting the patient in supine position for 5 minutes, blood pressure (BP) measurements were taken in all these patients using mercury sphygmomanometer in two successive out-patient department visits, and mean value of B.P. was taken. All patients were asked for duration of diabetes, hypertension and visual problems specifically. These patients were advised following investigations: - FBS. - RBS. - HbAlc. Relevant statistics, mean \& standard deviation were computed for variables. T-test was applied on hypertension (independent) and DM retinopathy (dependent) variables. Results: Systolic and diastolic blood pressure were significantly higher in the patients with retinopathy (mean systolic B.P $153.4 \pm 17.13$ and mean diastolic B.P. 84.1 \pm 9.26 ) than in those without retinopathy (mean systolic B.P. 130.65 \pm 11.94 and mean diastolic B.P $77.3 \pm 6.64$ ). There was significant correlation of diabetic retinopathy with systolic hypertension $(P<0.05)$ and diastolic hypertension $(P<0.001)$. Conclusion: There is strong association between diabetic retinopathy and hypertension. So early detection and treatment of hypertension can retard the development and progression of diabetic retinopathy.

Key words: $\quad$ Diabetes, Fundoscopy, Hypertension, Retinopathy.

Article Citation: Saqib A, Sarfraz M, Anwar T, Alam MA, Khan RR, Zafar ZA. Association of hypertension and diabetic retinopathy in type $2 \mathrm{DM}$ patients. Professional Med J 2020; 27(10):2056-2061. DOI: 10.29309/TPMJ/2020.27.10.4334

\section{INTRODUCTION}

Diabetes is a syndrome characterized by either absolute insulin deficiency or insulin resistance manifested clinically by polyurea, polydipsia, polyphagia or with any of the diabetes related complications. Type 2 diabetes is caused by insulin deficiency and insulin resistance. Type 2 diabetes causes high morbidity and mortality in Pakistani population and in the whole world as well. ${ }^{1}$ This is because of many diverse complications caused by uncontrolled diabetes. Most of these complications caused by vascular lesions. These vascular related complications are divided into microvascular and macrovascular complications. Diabetic retinopathy is one of the microvascular complication. ${ }^{2}$
If there is coexistent hypertension with diabetes, it accelerates micro and macrovascular complications. Most of the peoples with diabetes in our country also have hypertension (20-60\%), thereby endangering these patients to suffer from vascular complications. Hypertension is important in diabetes mellitus because it speed up both macrovascular and microvascular complications. ${ }^{3}$ Data regarding occurrence of diabetic hypertensive patients with retinopathy in our country is limited. As far as prevalence of diabetes in our population having age 25 years or above is concerned. It is $4.2 \%$ as indicated by National Health Survey of Pakistan. ${ }^{3,4}$

Total population of Pakistan is about 160 million, out of which about 7 million peoples suffering 
from diabetes. Regarding prevalence of DM Pakistan is at $8^{\text {th }}$ position in the world as reported by WHO. ${ }^{5,6}$ It is expected that Pakistan would be at $4^{\text {th }}$ position in the world in year 2025. ${ }^{7}$ Another 6 million are those who suffer from impaired glucose tolerance (IGT) ${ }^{8}$

There is high prevalence of diabetes type 2 in some local studies rising up to $11.1 \% .^{6}$ Duration of disease has significant impact on prevalence of various complications of diabetes. Patients having DM for $>10-12$ years, have prevalence of retinopathy about $33.3 \%$ being higher to those having less duration of diabetes. ${ }^{9}$

It is well known fact that reduction of blood pressure in hypertensive diabetic patients has caused reduction of vascular complications. This fact has been proved in various studies. ${ }^{10,11,12,13,14}$

Data from recent trials shows $\mathrm{BP}<130 / 80 \mathrm{mmHg}$ that causes significant reduction of microvascular complications. ${ }^{15}$ It is also clear that early aggressive control of blood pressure in diabetic patients can delay the occurrence and progression of retinopathy in type 2 diabetic patients. ${ }^{16,17}$ This study was carried out to emphasize the role of hypertension in diabetes related complications development and progression particularly retinopathy\& benefits of tight blood pressure control.

\section{MATERIAL \& METHODS}

The objective of this study is to evaluate the association of hypertension and diabetic retinopathy in type 2 diabetic patients.

This study was carried out on 100 type 2 diabetic patients between 40-70 years of ages with equal sex distribution in diabetic clinic at outpatient department of Independent University Hospital, Faisalabad. This study was carried out in 6 months from January 2019 to June 2019.

The sampling of this study was done by stratified sampling to limit the confounding variables and because data was heterogeneous.

\section{Inclusion Criteria}

All patients diagnosed as type 2 diabetes mellitus having age between $40-70$ years of either gender.

\section{Exclusion Criteria}

- Patients having type 1 diabetes.

- Patients having diabetes of either sex with age less than 40years or more than 70 years.

- Patients with type 2 diabetes not willing to take part in study.

- Patients having hypertensive retinopathy and other non- diabetes related retinopathy ( retinal vein occlusion, retinal telangiectasia, retinal macro-aneurysms)

\section{Data Collection Procedure}

All type 2 diabetic patients attending the outpatient department having age from 40-70years were reviewed and taken for study after their consent and approval by ethical committee of the hospital. All these patients screened for diabetic retinopathy using Wylchelin ophthalmoscope and slit-lamp examination after dilating the pupils with homatropine drops. The findings of fundoscopy were verified by an ophthalmologist on slitlamp examination. The patients having diabetic retinopathy were included in group $A$ (cases) and patients not having diabetic retinopathy were included in group $B$ (control).

Blood pressure was recorded in all patients using mercury saphigmo-manometer after patient being rested for 5 minutes in supine position. Fasting Blood Sugar, Random Blood Sugar and Hemoglobin Alc were carried out in all patients.

\section{Data Analysis Procedure}

Collected data was entered and analyzed by SPSS version 12. Qualitative variables like gender, presence of hypertension and retinopathy were presented as frequencies and percentages. Quantitative variables like age, weight, duration of diabetes and FBS, RBS, HaemoglobinA1c, systolic and diastolic blood pressure were presented as means and standard deviation. A $p$-value of $\leq 0.05$ was considered as significant.

\section{RESULTS}

Out of the 100 type 2 diabetic patients studied, the 
frequency of hypertension was $31 \%$ and males were $36 \%$ as compared to $64 \%$ females. The mean $\pm S D$ age of patients with retinopathy in group $A$ was $53.6 \pm 9.3$ years while it is $52 \pm 8.08$ year in group $B$ (P-value 0.369) (Table-I). Duration of diabetes was $8.3 \pm 4.5$ years in group $A, 7.5$ \pm 4.2 years in group $B$ and $P$-value was 0.367 (Table-II). The mean \pm SD of fasting blood sugar in group $A$ was $149.7 \pm 14.4 \mathrm{mg} / \mathrm{dl}$ while it was $144.4 \pm 16.14 \mathrm{mg} / \mathrm{dl}$ in group $B(P$ - Value 0.096) as shown in Table-III. The mean \pm SD of FBS in group $A$ was $165.9 \pm 11.25 \mathrm{mg} / \mathrm{dl}$ while in group $B$ was $163 \pm 13.3 \mathrm{mg} / \mathrm{dl}$ (P-value 0.25 ) shown in Table-IV. The mean SD of HbAlc in subjects with retinopathy (group A) was $7.8 \pm 0.41 \%$ while it was $7.7 \pm 0.28 \%$ in group $B(P$-value 0.144$)$ shown in Table-V.

Mean \pm SD systolic blood pressure in group $A$ was $153.4 \pm 17.13 \mathrm{mmHg}$ while it was $130.7 \pm$ $11.9 \mathrm{mmHg}$ in group $B(P$-value $<0.005)$ shown in Table-VI. The mean \pm SD of diastolic blood pressure in patients in group A was $84.1 \pm 9.3$ $\mathrm{mmHg}$ Jnd it was $77.3 \pm 6.6 \mathrm{mmHg}$ in group $B$ (P-value <0.001) shown in Table-VII.

So regarding mean age of patients, duration of diabetes and glycemic control (FBS, RBS \& HBAlc) there was not that much difference between the group $A$ \& group $B$. It is quite obvious that blood pressure was higher in patients with diabetic retinopathy (group $A$ ) than in those without diabetic retinopathy (group B).

So there was significant correlation of diabetic retinopathy with systolic hypertension ( $\mathrm{P}-$.022) and diastolic hypertension (P- .005).

\begin{tabular}{|c|c|c|c|c|}
\hline & Group A & \multicolumn{2}{|c|}{ Group B } & t-value \\
\hline Age & & & & P-Value \\
\hline Mean \pm SD & $536 \pm 9.3$ & 52.0 & \pm 8.08 & 0.902 \\
\hline N & 40 & 60 & & 0.369 \\
\hline
\end{tabular}

Table-I. Age of patients (year) for Group A \& B.

Key: Group A = Diabetic patients with retinopathy (case). Group B =Diabetic patients without retinopathy (control). P-Value: Highly Significant - $(P<0.01)$, Significant- $(0.01<P<0.05)$, Non-Significant $-(P>0.05)$

\begin{tabular}{|l|c|c|c|c|}
\hline \multicolumn{1}{|c|}{ Variable } & Group A & Group B & t-value & P-Value \\
\hline $\begin{array}{l}\text { Duration of Diabetes } \\
\text { (Mean } \pm \text { SD) }\end{array}$ & $8.25 \pm 4.5$ & $7.45 \pm 4.2$ & 0.906 & 0.367 \\
\hline N & 40 & 60 & \\
\hline
\end{tabular}

Table-II. Duration of diabetes (year) for Group A \& B.

Key: Group A = Diabetic patients with retinopathy (case). Group B = Diabetic patients without retinopathy (control) P-Value: Highly Significant - $(P<0.01)$, Significant- $(0.01<P<0.05)$, Non-Significant - $(P>0.05)$

\begin{tabular}{|c|c|c|c|c|}
\hline Variable & Group A & Group B & t-Value & P-Value \\
\hline Mean \pm SD & $149.72 \pm 14.45$ & $144.42 \pm 16.14$ & 1.679 & 0.096 \\
\hline N & 40 & 60 & \\
\hline
\end{tabular}

Table-III. Fasting blood sugar ( $\mathrm{mg} / \mathrm{di})$ in Group A \& B.

Group $A=$ Diabetic patients with retinopathy (case). Group B = Diabetic patients without retinopathy (control).

P-Value: Highly Significant - $(P<0.01)$, Significant- $(0.01<P<0.05)$, Non-Significant - $(P>0.05)$

\begin{tabular}{|c|c|c|c|c|}
\hline Variable & Group A & Group B & t-Value & P-Value \\
\hline Mean \pm SD & $165.9 \pm 11.25$ & $163 \pm 13.3$ & 1.158 & 0.25 \\
\hline N & 40 & 60 & 158 \\
\hline
\end{tabular}

TABLE-IV. Random blood sugar $(\mathrm{mg} / \mathrm{dl})$ in Group A \& B.

Group A = Diabetic patients with retinopathy (case). Group B = Diabetic patients without retinopathy (control)

P-Value: Highly Significant - $(P<0.01)$, Significant- $(0.01<P<0.05)$, Non-Significant - $(P>0.05)$ 


\begin{tabular}{|c|c|c|c|c|}
\hline Variable & Group A & Group B & t-Value & P-Value \\
\hline Mean \pm SD & $7.79 \pm 0.41$ & $7.69 \pm 0.28$ & \multirow{2}{*}{1.474} & \multirow{2}{*}{0.144} \\
\hline $\mathrm{N}$ & 40 & 60 & & \\
\hline
\end{tabular}

\begin{tabular}{|l|c|c|c|c|}
\hline \multicolumn{1}{|c|}{ Variable } & Group A & Group B & t-Value & P-Value \\
\hline Mean \pm SD & $153.42 \pm 17.13$ & $130.65 \pm 11.94$ & 7.837 & $<0.005$ \\
\hline N & 40 & 60 & \\
\hline
\end{tabular}

Table-VI. Systolic blood pressure $(\mathrm{mmHg})$ in Group A \& B.

Group A = Diabetic patients with retinopathy (case). Group B = Diabetic patients without retinopathy (control P-Value: Highly Significant - $(P<0.01)$, Significant- $(0.01<P<0.05)$, Non-Significant - $(P>0.05)$

\begin{tabular}{|c|c|c|c|c|}
\hline Variable & Group A & Group B & $\mathrm{t}$-Value & P- Value \\
\hline Mean + SD & $84.12+9.3$ & $77.3+6.64$ & \multirow{2}{*}{4.292} & \multirow{2}{*}{$<0.001$} \\
\hline $\mathrm{N}$ & 40 & 40 & & \\
\hline
\end{tabular}

\section{DISCUSSION}

There is clear evidence that strict control of hypertension in patients with type 2 DM has resulted in $37 \%$ reduction in microvascular complications in U.K. Prospective Diabetes Study Hypertension in diabetes study ((UKPDS-HDS). ${ }^{18}$ It has also been shown in various research data that goal of diastoloic blood pressure should be even $<80 \mathrm{mmHg}$. Data regarding optimal level of systolic blood pressure (SBP) control is not established. In the light of various ongoing studies the goal of SBP should be $<130 \mathrm{mmHg} .{ }^{19}$

The data regarding the effect of hypertension in diabetic retinopathy is sparse in our country. Different researches in our country regarding frequency of HTN in type 2 DM with retinopathy show variable results ranging from $37 \%$ to $50 \%$. While $33.3 \%$ frequency of HTN in diabetic non proliferative retinopathy was found to be in one of the study conducted in Sir Ganga Ram Hospital, Lahore. In the same study HTN was found in $21.5 \%$ of diabetic patients with proliferative retinopathy. ${ }^{20}$

One of the studies shows increase prevalence of hypertension (64.6\%) in type 2 diabetic retinopathy with predominant female patients conducted by shera et al. This study also shows that prevalence of rnicro-vascular complications increased with hypertension, duration of diabetes, obesity \& poor glycemic control (HbAlc $>8 \%) .{ }^{21}$

In one of the other study conducted in Punjab showed that $42.8 \%$ diabetics were hypertensive (38.3\% male \& $45.5 \&$ female). Frequency of hypertension was higher in those who were having the diabetes for longer time, advanced age, poor glycemic control \& in obese..$^{22}$

In this study, the frequency of hypertension is $31 \%$ (males $34 \%$ \& females $66 \%$ ) which is almost, comparable with $37 \%$ and $42.8 \%$ shown in two local studies. The frequency of retinopathy in this study is $40 \%$ (non-proliferative $30.4 \%$ \& proliferative $9.6 \%$ ), which is comparable with study done at Sir Ganga Ram Hospital, Lahore.

A relation between diabetic retinopathy and various risk factors was studied in one of the research done by Van Leiden et al. ${ }^{23}$ There was significant correlation between diabetic retinopathy with age of the patient (mean age was $64.8 \pm 6.1$ ) and HbA1c (P-value was <0.03) and systolic hypertension (P-0.02) and diastolic hypertension. There was no significant correlation 
between diabetic retinopathy with fasting blood sugar (P 0.09).

In present study, no significant correlation was found between diabetic retinopathy with age of the patient, duration of diabetes, fasting blood sugar (FBS), random blood sugar (RBS) and $\mathrm{HbA}_{1 \mathrm{c}}$. But significant correlation was found between diabetic retinopathy with systolic hypertension $(P<0.05)$ and diastolic hypertension $(P<0.001)$.

It is clearly evident that this study population is about 10 years younger than the study population of Van Leiden et al study. Similarly mean for the duration of diabetes was much lower for our study as compared to Van Leiden et al study. As duration of diabetes is a significant risk factor in the progression of diabetic retinopathy so the insignificant correlation between diabetic retinopathy with age of the patient and duration of diabetes and glycemic control in our study might be explained by the younger population \& lower duration of diabetes as well as small study population.

The correlation of hypertension with diabetic retinopathy in this study is significant and is comparable with that of UKPDS-HDS, Shera et al. and Van Leiden et al. studies, but in this study significant correlation of diastolic blood pressure with DM retinopathy does not correlate with Van Leiden et al. findings. This difference may be explained because of antihypertensive medications effects used in Van Leiden et al.

\section{CONCLUSION}

There is strong association between hypertension and diabetic retinopathy as evident in this study. Among the different risk factors which have role in the progression of diabetic retinopathy, Hypertension is one of the important modifiable risk factor. Further studies are recommended to determine the role of antihypertensive agents in the diabetic retinopathy.

Copyright@ 24 July, 2020.

\section{REFERENCES}

1. The expert committee on the diagnosis and classification of diabetes mellitus. Report of the expert committee on the diagnosis and classification of diabetes mellitus. Diabetes Care 2003; 26 (Suppl 1): S 5-20.

2. Sowers JR. Diabetes mellitus and vascular disease. Hypertension. 2013; 61(5):943-7.

3. Chen G, McAlister FA, Walker RL, et al. Cardiovascular outcomes in Framingham participants with diabetes: The importance of blood pressure. Hypertension. 2011; 57:891-7.

4. Samad A, Farooqui S. Relative, frequency of arterial hypertension in patients with diabetes mellitus, current perspective. Pak J Cardiol 2003; 14(1): 21-8.

5. Pakistan Medical Research Council. National Health Survey of Pakistan, Islamabad. Pakistan Medical Research Council; 1997:54.

6. Shera AS, Rafique G, Khwaja. IA, Baqai S, King $\mathrm{H}$. Pakistan National Diabetes Survey prevalence of glucose intolerance and associated factors in Baluchistan Province. Diabetes Res Clin Pract 1999; 44: 49-58.

7. Basit A, Hydrie MZI, Ahmed K, Hakeem R. Prevalence of diabetes, impaired fasting glucose and associated risk factors in a rural area of Baluchistan province according to new ADA criteria. J Pak Med Assoc 2002; 52: 357-60.

8. Memon BA, Bhatti K. Prevalence of diabetes mellitus in Sukkur region. Pak J Med Res 2002; 41:19-22.

9. Kayani H, Rehan N, Naeem- Ullah. Frequency of retinopathy among diabetics in a teaching hospital of Lahore. J Ayub Med Coll Abottabad 2003; 15 (4): 536.

10. Cushman WC, Evans GW, Byington RP, et al. ACCORD Study Group. Effects of intensive blood-pressure control in type 2 diabetes mellitus. N Engl J Med. 2010; 362:1575-1585.

11. Rudnisky CJ,Wong BK,Virani H, Tennant MTS. Risk factors for progression of diabetic rtinopathy in alberta first nations communities. Can $\mathrm{J}$ ophthalmol. 2017; 52(1):19-29.

12. Emdin A, Rahimi K, Neal B, Callender T, Perkovic V, Patel A. Blood pressure lowering in type 2 diabetes; A systematic review and meta-analysis. JAMA. 2015; 313(6):603-15. 
13. Song P,Yu J, Chan Ky, Chan KY, Theodoratou E, Rudan I. Prevvalence, risk factors and burden of diabetic retinopathy in china: A systematic review and metaanalysis. J Glob health. 2018; 8(1):010803.

14. Chen WP, Shan W, Song E; etal. Combined effect of glycemic and blood pressure control on diabetic retinopathy among Chinese with type 2 diabetes mellitus. Diabetol metab syndr. 2018; (10): 73.

15. American Diabetes Association Standards of medical care in diabetes --2011. Diabetes Care. 2011; 34:S11-S61.

16. UK Prospective Diabetes Study Group Tight blood pressure control and risk of macrovascular and microvascular complications in type 2 diabetes: UKPDS 38. BMJ. 1998; 317:703-713.

17. Song E, Qian DJ, Wang S, XU C, Pan CW. Refractive error in Chinese with type 2 diabetes and its association with glycemic control. Clin Exp optom. 2018; $101(2): 213-9$.

18. Heart Outcomes Prevention Evaluation Study Investigators. Effects of ramipril on cardiovascular and microvascular outcomes in people with diabetes mellitus: results of the HOPE study and MICROHOPE sub study. Lancet 2000; 355:253-259.
19. Kikuya M, Hansen TW, Thijs L, et al.; IDACO investigators. Diagnostic thresholds for ambulatory blood pressure monitoring based on 10-year cardiovascular risk. Blood Press Monit 2007;12:393395

20. Chaudhary GM Din. Diabetes and hypertensionExperience in $\mathbf{3 2 7 5}$ diabetic patients. Pak J Med Sci 2001; 17: 11-4.

21. Shera AS, Jawad F, Maqsood A, Jamal S, Afial M, Ahmed U. Prevalence of chronic complications and associated factors in type 2 diabetes. J Pak Med Assoc 2004; 54: 54-9.

22. Hashim R, Khan F, Khan D, Saukat A. Prevalence of macrovascular complications in diabetics of WAH, District Rawalpindi. J Pak Med Assoc 1999; 49: 8-11

23. Van Leiden H, Dekker JM, Mol AC, Nijpels G, Heine RJ, Bouter LM, et all. Risk factors for incident retinopathy in a diabetic and non-diabetic population: The Hoorn study. Arch Ophthalmol 2003; 121: 245-51.

\begin{tabular}{|c|l|l|}
\hline \multicolumn{3}{|c}{ AUTHORSHIP AND CONTRIBUTION DECLARATION } \\
\hline Sr. \# & \multicolumn{1}{|c|}{ Author(s) Full Name } & \multicolumn{1}{|c|}{ Contribution to the paper } \\
\hline 1 & Ali Saqib & Data collection. \\
\hline 2 & Muhammad Sarfraz & Data analysis. \\
\hline 3 & Touseef Anwar & Compilation of resutls. \\
\hline 4 & Muhammad Absar Alam & Discussion writing. \\
\hline 5 & Rizwan Rasul Khan & Review \& Introduction. \\
\hline
\end{tabular}

